\title{
The deformation characteristics of buried HDPE transfer lines in trenches under the effect of temperature
}

\author{
Necmettin Polat $\mathbb{1}^{1}$, Can Erenson* $\mathbb{D}^{2}$, Niyazi Uğur Terzi $\mathbb{(}^{3}$ \\ 1 Aksaray University, Engineering Faculty, Civil Engineering Department, 68100 (Turkey), necmettinpolat@hot- \\ mail.com; canerenson@aksaray.edu.tr; nterzi@aksaray.edu.tr \\ *Correspondence: canerenson@aksaray.edu.tr
}

Received: 11.01.2021; Accepted: 22.11.2021; Published: 31.12.2021

Citation: Polat, N., Erenson, C., and Terzi, N. U. (2021). The deformation characteristics of buried HDPE transfer lines in trenches under the effect of temperature. Revista de la Construcción. Journal of Construction, 20(3), 452-462. https://doi.org/10.7764/RDLC.20.3.452.

\begin{abstract}
Today, the use of high-density polyethylene (HDPE) transfer lines is increasing day by day for drinking water, wastewater, sewerage networks, rainwater drainage lines, water transport structures, and natural energy sources, etc. In this study, flexible HDPE pipes were embedded in a trench to expose them to variable relative density and different thermal conditions so that the resulting deformation behavior could be investigated. Displacements and elastic strain values in the crown and spring line regions were measured. The main aim of this research was to determine the behavior of HDPE pipes under temperature effects within the framework of geotechnical principles to reflect real field conditions. As a result, pipes subject to vertical loading were tested under different relative density and thermal conditions. In the experiments carried out in a silica sandy trench, the deformations increased due to an increase in relative density. The maximum displacements and bending moment values were obtained at $50^{\circ} \mathrm{C}$, which was the maximum thermal condition applied. An increase in temperature increased the deformation values due to the resulting decrease in the modulus of elasticity.
\end{abstract}

Keywords: buried pipe, deformation behavior, high-density polyethylene, silica sand, thermal effects.

\section{Introduction}

Population growth leads to an increase in needs and demands. To meet those basic needs with a healthy, economical, easy, and long service life, resources are transported by buried, above-ground, and floating transfer lines such as pipes. From past to present in the pipeline industry, mostly concrete, reinforced concrete, steel, PVC (polyvinyl chloride) and HDPE pipes have been preferred due to their advantageous engineering properties. Compared to others, HDPE pipes are widely used across the world as a type of flexible pipe used for fluid, gas, and solid matter due to their numerous advantages such as high flexibility, high tensile strength, low production cost, easy installation, suffering minimal impact from underground movements exhibiting a high cracking and impact resistance, low internal surface roughness, allowing subsea processing, resistant to ultraviolet rays and chemicals, a long service life, and being tasteless and odor-free, which all play an effective role in the preferential use of HDPE pipe.

In the trench design, it was aimed to predict the possible static and dynamic loads that will affect the HDPE material. Transfer line installation is conducted by considering the ideal burial depth. In addition, the burial depth should be carefully calculated to prevent frost heave affecting the installation of the pipes in cold climatic conditions and damaging the system 
(Trautmann \& O'Rourke, 1985). It is of great importance to determine the freeze-thaw properties of the system under different climatic conditions when taking precautions.

The effect of temperature fluctuations plays a significant role in pipe behavior. As a result of frozen water thawing, the soil texture adopts a porous formation (Ural \& Gergin, 2020). Therefore, the bearing capacity, settlement, and collapse mechanisms also change under the effect of temperature. Besides changing the material rigidity of polyethylene (PE) products through factors such as the ambient temperature, the temperature of the transported substance and external effects also affect the material behavior. Therefore, the service life and failure mechanism of the material when ductile or brittle are related to the stability and rheological condition of the transfer lines. Since the temperature effect changes the internal structure of the polymer-based HDPE material under the effect of a load, variable behaviors were observed in the system. In particular, the high deformation potential of polymer-based materials, which have many advantages within the scope of their intended use, indicates that the material must be accurately defined, classified, determined, and installed according to its characteristics. In this respect, the deformation properties of HDPE100 pipes buried in a trench under different relative density conditions (50\%, $60 \%, 70 \%)$ and at three different temperature variables $\left(-7^{\circ} \mathrm{C}, 26^{\circ} \mathrm{C}, 50^{\circ} \mathrm{C}\right)$ were investigated.

The main reason for the previously mentioned advantages of HDPE materials is that they contain polymer-based chemically connected structures. HDPE pipes used for their flexibility effectively maintain their serviceability even under extreme deformations in comparison to rigid pipes. However, when critical stresses are reached at certain temperature values, the decrease in elasticity modulus (E) resulting in a weakening of the bonds in the polymer structure makes it difficult to maintain within the allowable deformation limits. This case highlights the importance of establishing optimal compactness under specified temperature conditions (Polat, 2020). In addition, the magnitude of the load acting on the pipe, the number of load steps, the loading speed, and the load duration can be given as examples of other parameters that affect the pipe behavior. Before installation, laboratory tests are important as field tests in terms of design and quality conformity criteria.

In published literature, the cases where many polymer-based materials are exposed to thermal effects have generally been considered by interpreting tensile tests and the elongation relationships of the material properties. Among these tests, there is no study that reflects changes in behavior in trenches. In order to determine the real site behaviors in the laboratory, materials should be tested in accordance with field conditions.

Polyethylene materials have been introduced into the market for commercial purposes over the past four decades and a high-density was achieved using low pressure. Karl Zieger and Erhard Holzkamp who studied polyethylene at the Kaiser Wilhelm Institute won the Nobel Prize in chemistry (Gabriel \& Moran, 1998; Kapischke \& Pries, 2014). Afterwards, Karl Zieger was deemed worthy of the title of the father of HDPE given his contribution as a result of the techniques he developed (Seymour, 1989). The internal structure and interactions of a polymer that provides such important advantages can change according to temperature-dependent structural factors. Due to the molecular structure of polyethylene, it has high insulation and high strength properties. Therefore, it can be used to transfer important resources such as petrol, natural gas, and water. All these developments occurred within the scope of the durability provided by the crystal phases in the polymer structure and the flexibility delivered by the amorphous phases. Thermal effects in these structures cause the bonds shown in Figure 1 to weaken and the material behavior to change.

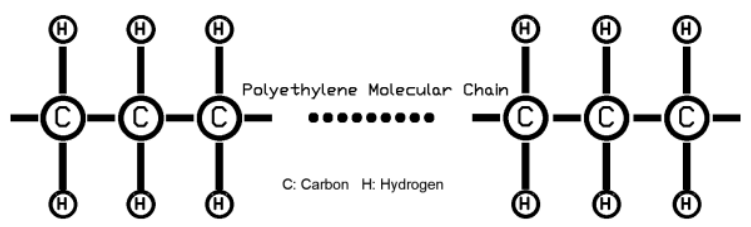

Figure 1. A perspective of the polyethylene molecule.

In the development process of polyethylene, valuable studies at the stages of definition, classification, and evaluation have contributed to the literature and the sector. 
To give an example of the studies examined in this context: In a study investigating the rheological, molecular, thermal, and mechanical properties of PE products, weight, density, viscosity, melting, crystallization, and stress-strain characteristics were studied by mixing different percentages of HDPE and linear LDPE (Shaidullin et al., 2020). As a result, the researchers presented the preferred mixing ratios that deliver the properties required in particular areas of use. In another study, HDPE, LDPE, and HDPE-LDPE mixtures were tested according to melt strength and drawability criteria (Liang, 2019). As a result, it was revealed that extrusion temperature and elongation rates are important for the melt strength and drawability of HDPELDPE mixtures during elongation flow. Also, according to the drawability test, the extension load of HDPE samples was found to be higher than LDPE or the mixtures.

The backbone atoms of HDPE form a zigzag-shaped formation and they form a thermoplastic construction by transforming the linear structure chain into a cross-linked structure (Callister \& Rethwisch, 2015). This situation transforms the HDPE structure into a polymer that solidifies due to thermal effects, and this layout changes the behavior of the PE. Crystal polymer density has a direct effect on linear and branched-chain types. Increasing the level of crystallinity provides an improvement in the PE structure in terms of tensile strength, stiffness, density, and yield.

HDPE materials are produced in two different ways with low pressure or high pressure (Lepoutre, 2013). For both methods, production temperatures, ideal gas temperatures in the catalytic processes, and optimal product temperatures are controlled because the temperature effects can be critical, especially for thin sections of HDPE materials, and HDPE exposed to hightemperature effects. In this respect, it is important to consider temperature effects in the design, installation, application, and service stages of transfer lines. Another difference between PE products under pressure and temperature is that the HDPE molecular structure is the long and branched-chain type. In LDPE, this structure is in the form of short and branched lines and these affect the molecular structure (Cheng, 2008). Therefore, HDPE is flexible because it shows less crystallization as a result of these formations and has a more durable, dense, and long service life due to the strong bonds it contains.

In addition to these HDPE characteristics, (Tarani et al., 2017) emphasized that HDPE with a thermal conductivity of 0.44 $\mathrm{W} / \mathrm{m} . \mathrm{K}$ has an important position in the sector for the transportation of materials. (Tavman et al., 2011) explained the reason for these uses in their studies stating that thermal conductivity decreases due to the increase in the quantity of heat. Generally, HDPE transfer lines are widely preferred in geothermal facilities, hot water transfer lines, and the cooling units of thermal and nuclear power plants. Therefore, it is necessary to determine the characteristics, behavior, and mechanisms of these lines. In this context and under the effects of temperature, (Sadr-Al-Sadati \& Jalili Ghazizadeh, 2019) examined the flexibility properties; (Krishnaswamy, 2005) observed longitudinal cracks, ductility effects, and viscoelastic-thermoplastic behavior along the pipeline in water treatment plants; and (Merah et al., 2006) investigated the decrease in yield strength depending on the temperature increase.

Apart from the laboratory tests, there are studies in published literature using numerical analysis to examine thermal effects on HDPE. One of them was conducted on electrofusion-type HDPE pipe joints. Heat treatment was applied in the jointing processes of HDPE pipes and the integrity of the two separate products was investigated. (Khademi-Zahedi \& Alimouri, 2018) investigated the effects of factors such as soil-structure interaction, traffic loads, internal and external pressure conditions, and climatic conditions on local stresses in pipe joints. In the numerical analysis performed using ANSYS software, the stresses on the joints were taken into consideration and the researchers determined the ideal embedment depths within the scope of these criteria. (Li et al., 2012) remarked that time-dependent temperature has significant effects on HDPE pipe behavior and stated that pipe thermal expansion is generally neglected while further emphasizing that this factor should be taken into account. As a result of the numerical analysis obtained by the researchers using the ABAQUS software under loading, they revealed that the stresses caused by the thermal effects are as crucial as the soil conditions.

In another study, $\mathrm{HDPE}$ pipes at $30^{\circ} \mathrm{C}, 40^{\circ} \mathrm{C}, 50^{\circ} \mathrm{C}, 60^{\circ} \mathrm{C}$, and $70^{\circ} \mathrm{C}$ were tested in water using the nonlinear finite element program Z-Soil. The analysis was used to determine, the secant deformation modulus and yield strength of HDPE pipes exposed to stress. In addition, it was concluded that the surface pressure and internal pressure performances were higher between the $30^{\circ} \mathrm{C}$ and $70^{\circ} \mathrm{C}$ temperature conditions (Alawaji, 2004). 
A wide range of studies have been conducted on HDPE materials such as tensile tests, thermal effect tests, vertical loading tests, frost action studies as can be seen in published literature or these tests have been modeled and collectively analyzed by various software. However, their evaluations were not interpreted together in terms of geotechnical perspective within the scope of laboratory tests under the effect of temperature, trench, and loading. Considering these effects separately gives predictable and linear results for behavior, but evaluating all conditions together is crucial in terms of safety, cost, and long service life. The main aims of this research were to determine the behavior of HDPE pipes under temperature effects within the frame of geotechnical principles, to reflect the real field conditions realistically, and provide a good understanding of these conditions.

\section{Materials}

In the laboratory experiments, silica sand representing the trench and HDPE100 pipes were used. The experiments were carried out in a rigid test box following the standards, taking into account the boundary conditions. During the experiments, loading steps and deformation measurements were collected synchronously.

\subsection{Silica sand}

In the laboratory tests, silica sand was used as a trench material that had no additives and was uniformly compressible. To reflect equivalent engineering properties in every section of the trench, homogeneous sand was formed in each region of the test box. Therefore, silica sand with a low coefficient of uniformity was preferred in the study. Silica sand was compacted into the rigid test box in layers of 10 centimeters for each test. After, for each layer, a $10 \mathrm{~kg}$ weight was dropped onto it. Density and weight controls were performed according to the index properties of silica sand. Characteristic parameters of the silica sand used in the tests carried out in three different relative density conditions are given in Table 1.

Table 1. Characteristic parameters of silica sand.

\begin{tabular}{r|lllll}
\hline & \multicolumn{3}{c}{ Relative density } & Specific gravity $(\mathrm{Gs})$ & \multicolumn{2}{c}{2.65} \\
\cline { 2 - 4 } Criteria & $50 \%$ & $60 \%$ & $70 \%$ & Soil class (USCS*) & SP \\
\hline Weight per unit volume $\left(\gamma ; \mathrm{kN} / \mathrm{m}^{3}\right)$ & 14.7 & 16.0 & 16.6 & Coefficient of uniformity $\left(\mathrm{C}_{\mathrm{U}}\right)$ & 2.11 \\
Angle of internal friction $\left(\phi^{\circ}\right)$ & 33 & 36 & 39 & Effective diameter & 0.198 \\
Elasticity modulus $(\mathrm{E}) \mathrm{MPa}$ & 34 & 57 & 68 & Coefficient of curvature $\left(\mathrm{C}_{\mathrm{C}}\right)$ & 0.32 \\
\hline
\end{tabular}

Silica sand used in the tests was acquired from Şile, İstanbul. Washing, enrichment, classification, and dewatering processes were conducted on the silica sand. The sand prepared by the producer was untouched by human hands with a maximum AFS clay of $0.5 \%$, a maximum humidity of $7 \%$, and a degree of homogeneity of $70 \%$ or above.

\subsection{HDPE100 pipe}

High quality and standardization are very important in the production process. Therefore, comprehensive experiments were carried out in the R\&D laboratories of the company from which the HDPE pipes were supplied. In the laboratory experiments, pipes were tested under quality and conformity criteria such as pipe diameter, pipe curvature, wall thickness, and polyethylene content. At the onset of every test identical and undisturbed pipes were used. After testing finished, each pipe was examined for deformation. Engineering properties and chemical properties obtained from the R\&D tests on the pipes are indicated in Table 2.

Table 2. Technical data of HDPE pipe.

\begin{tabular}{cccc}
\hline Elasticity modulus (E) & Density $(\gamma)$ & Poisson ratio $(v)$ & Production temperature \\
$900 \mathrm{MPa}$ & $0.945-0.965 \mathrm{~g} / \mathrm{cm}^{3}$ & 0.42 & $>100^{\circ}$ \\
\hline Crystal structure ratio & Transparency ratio & Melting point & Rupture stress at $23^{\circ} \mathrm{C}$ \\
$90 \%$ & $90 \%-95 \%$ & $135^{\circ}$ & $>21 \mathrm{MPa}$ \\
\hline
\end{tabular}


The pipe had an outside diameter of $280 \mathrm{~mm}$ and a wall thickness of $9.8 \mathrm{~mm}$. The length of the HDPE pipe specimen selected was $500 \mathrm{~mm}$ according to the rigid test box dimensions. The regions of the pipes are denominated the crown at the top, the springlines (left \& right) at the sides, and the invert at the bottom. For standardization of experiments and calibration of measurements, pipes were produced at minimum speed as equivalent as possible. Also, quality and conformity criteria were performed for each pipe sample. As a result, it was determined that all pipe samples conformed to the standards and were almost identical.

\subsection{Rigid test box}

As a result of the observations in the studies investigating the soil-pipe interactions, the depth of the test box should be at least 1.5 times the pipe diameter (Laidlaw, 1999; Terzi, 2007). $280 \mathrm{~mm}$ diameter pipes were used in the laboratory experiments and the width between 640 - $690 \mathrm{~mm}$ was approved for the (ASTM D2321-00, 2000) standard. Accordingly, there are no breaches in terms of boundary conditions since the rigid test box width used in tests is $700 \mathrm{~mm}$.

\section{Testing procedure}

\subsection{Sand filling}

Primarily, a $150 \mathrm{~mm}$ bedding layer was placed and compressed inside the trench. The HDPE pipe was positioned on this bedding layer. Then a $500 \mathrm{~mm}$ layer was placed on the HDPE pipe under controlled relative density conditions.

\subsection{Loading}

Vertical loading was carried out by applying air pressure to the flat-sectioned rubber membrane positioned on the sand fill. During loading, a compressor with a capacity of 12 bar (1200 kPa) incrementally pressurized the rubber membrane every minute. In each stress step, 0.5 bar was increased. The loading process was continued until the deformations stabilized and the stresses were absorbed in the trench. The experiments were completed by applying an ultimate vertical load of $400 \mathrm{kPa}$ to the soil surface.

\subsection{Measurements}

Vertical and lateral deformations of the pipe section were measured by linear variable differential transformers (LVDTs) and strain gauges at the midpoint of the pipe. LVDTs were positioned to the crown and springline of the HDPE pipe. Strain gauges were bonded on the crown, springlines (left and right), and base region so that the bending moment values could be calculated. The pressure values in the loading stage were read by a tire pressure gauge integrated into the rubber membrane. Simultaneously, the deformation values were taken by the data acquisition unit. Additionally, the values of deformation, temperature, and loading were observed instantly with cameras and synchronized. The displacement values of the crown region and springlines from the midpoint of the pipe length were obtained by using LVDTs. Mechanical measurements of the vertical displacements of the crown and the horizontal displacement of the springlines were determined.

The bending moments $\left(\mathrm{M}_{\mathrm{B}}\right)$ occurring in the crown and springlines were read by strain gauges. The strain is the amount of deformation of a body due to an applied force (Patel \& Srinivas, 2012). In the study, strains were calculated according to the equations in the manuals of the company that provided the strain gauges. Bending moments were found as a result of the strain values gathered according to millivolt changes. Thus, enforced zones of the pipe section were detected under vertical load in all temperature conditions. The resistance of connecting cables changes under the temperature effect. A change in the ambient temperature of $1-2^{\circ} \mathrm{C}$ changes the strain values by 10 to $20 \mu \varepsilon$. These criteria were taken into account in the strain calculations. The formation of LVDTs and strain gauges on the pipe section is shown in Figure 2. 


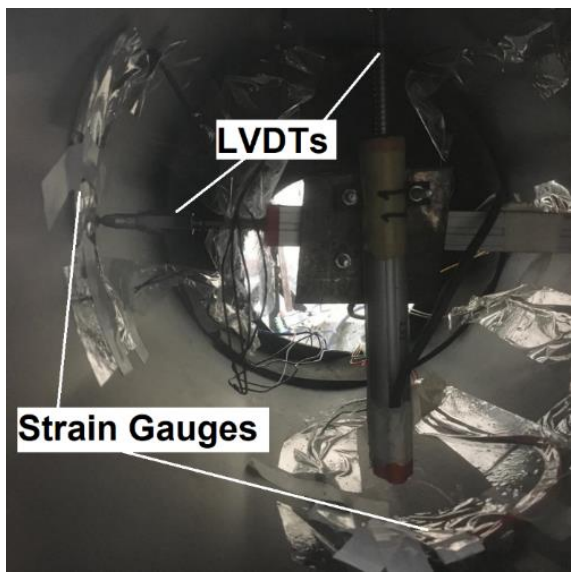

Figure 2. Formation of LVDTs and strain gauges.

\subsection{Heat application}

The temperature effect applied to the HDPE pipe samples was affected by using thermal stripes. A temperature sensor placed on thermal stripes is connected to the control panel. The temperature is kept stable at $50^{\circ} \mathrm{C}$ and vertical stress begins under this condition. During the experiments, thermal stripes work continuously. The heating system installed on the HDPE transfer line is given in Figure 3. Thermal stripes are wound loosely not to affect deformation values.

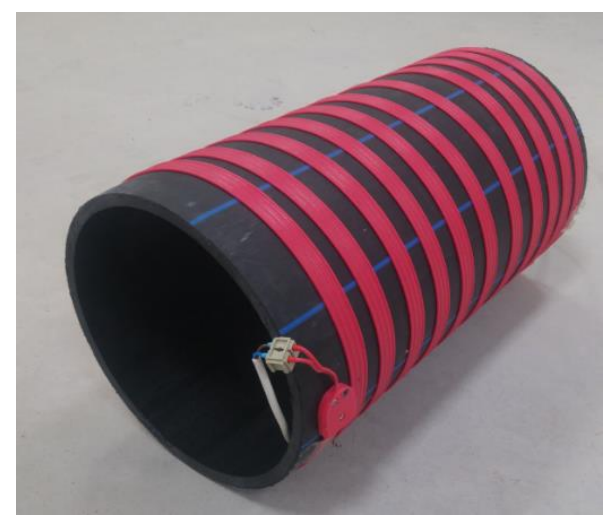

Figure 3. HDPE pipe and thermal stripes.

\subsection{Cooling}

In the cooling system, bent copper pipes were used to provide the $-7^{\circ} \mathrm{C}$ coldness. Helical copper pipes were located in the system connected to an air conditioner. The experiments were conducted at $-7^{\circ} \mathrm{C}$ with reference to the control panel on the air conditioner. During the experiments, the ambient conditions were fixed between $-7^{\circ} \mathrm{C}$ and $-8^{\circ} \mathrm{C}$. The system installed for cooling operations and after the installation is completed, the final form of the test system is as in Figure 4. 


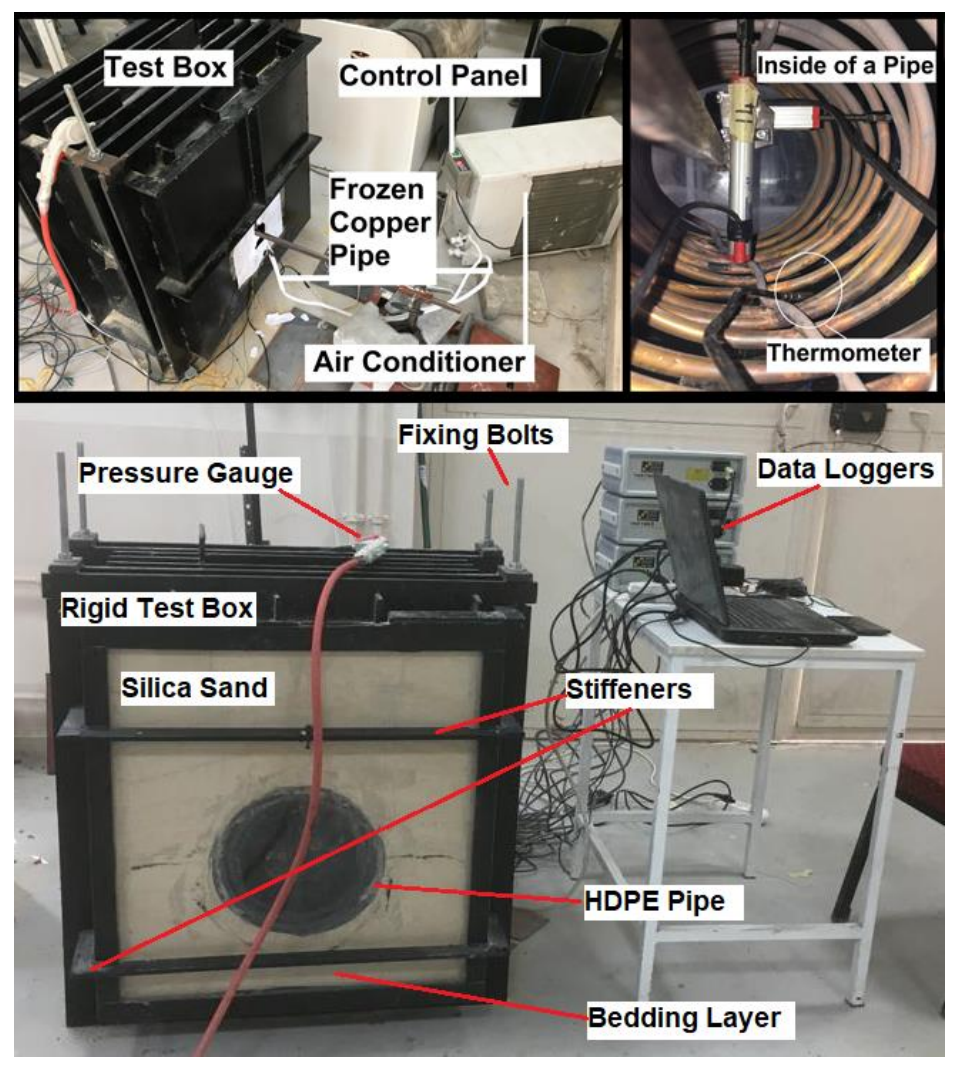

Figure 4. Cooling process and test system.

\section{Test results and discussion}

This study examined the deformation behavior of HDPE transfer lines buried in a trench under different relative density conditions and thermal effects. As a result of the laboratory experiments carried out under the effect of loading and temperature for $50 \%, 60 \%$, and $70 \%$ relative density (Rd) conditions, vertical displacements at the crown, and average lateral displacements at the springline region are given in Figures 5, respectively. In the graphs, heat application, room conditions, and cooling process are shown in red, black, and blue lines, respectively. 

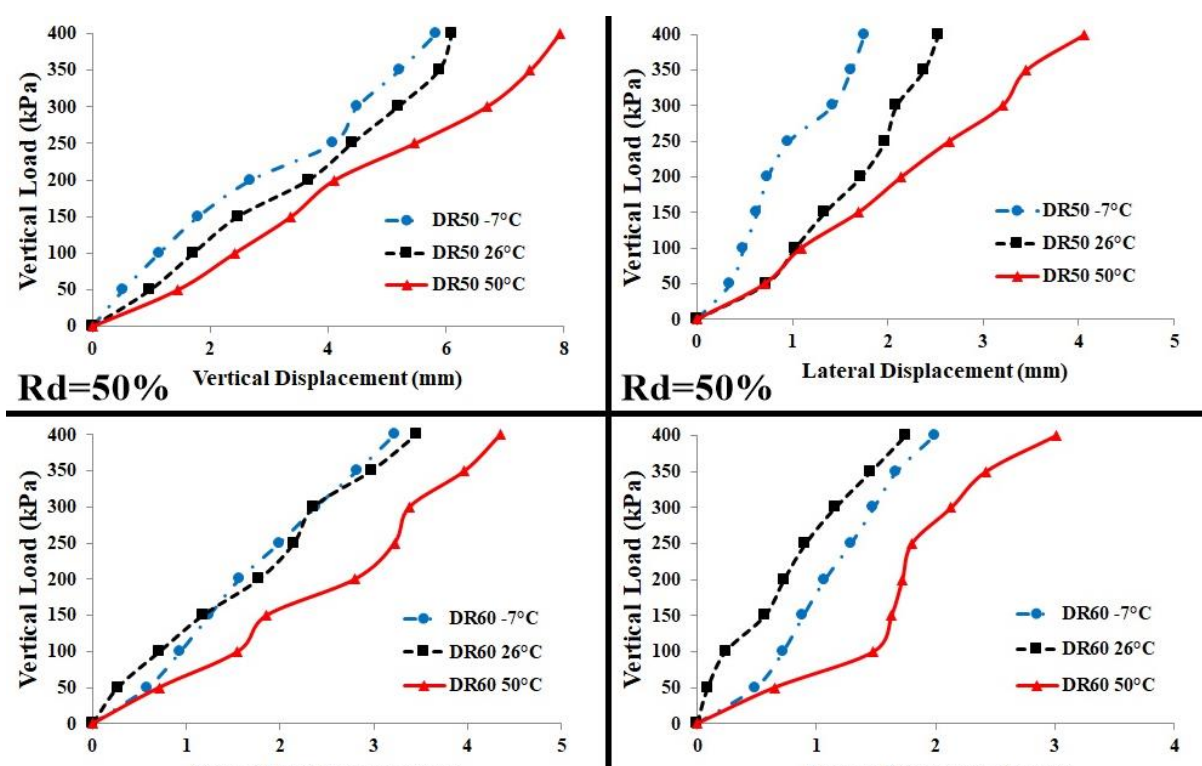

$\underline{\mathbf{R d}=60 \%}$ Vertical Displacement $(\mathrm{mm})$
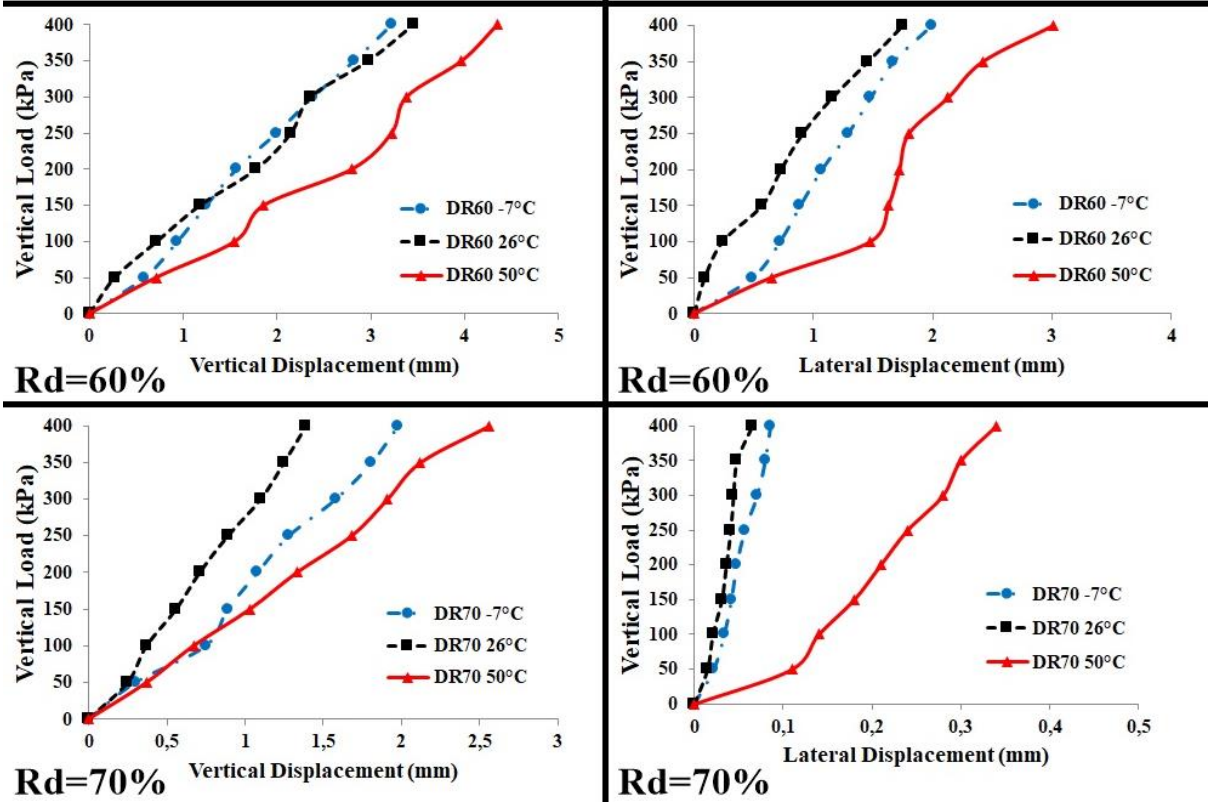

Figure 5. Vertical and lateral displacements for $50 \%, 60 \%$, and $70 \%$ relative density condition at $-7^{\circ} \mathrm{C}$, $+26^{\circ} \mathrm{C}$, and $+50^{\circ} \mathrm{C}$.

In all experiments, the displacement values at the crown of the pipe decreased as a result of the increase in the relative density of soil. In the experiments conducted at room temperature conditions $\left(+26^{\circ} \mathrm{C}\right)$ deformations for both crown and springlines were found to be lower than for other conditions. As expected, the greatest deformation levels were observed at $+50^{\circ} \mathrm{C}$ for the crown and springlines of the pipe, under similar conditions for all relative density cases. Because of the increasing flexibility and the decreasing elasticity modulus observed due to the temperature increase, the HDPE materials changed shape. In addition, for all relative density conditions, the deformation data obtained at $-7^{\circ} \mathrm{C}$ showed closer results to room temperature conditions $\left(+26^{\circ} \mathrm{C}\right)$ compared to $+50^{\circ} \mathrm{C}$. In this respect, an increase from 24 to $25^{\circ} \mathrm{C}$ showed more deformation than a temperature decrease from 32 to $33^{\circ} \mathrm{C}$.

In this study, the engineering properties and behavior of buried flexible HDPE pipes under thermal and cooling effects were investigated. Results revealed that the rigidity of the polymer-based HDPE material decreased under temperature. As stated above, it was observed that even a difference of 24 to $25^{\circ} \mathrm{C}$ caused a significant decrease in pipe rigidity. The bending moment values evaluated in the data loggers within the scope of the experiments are presented in Figure 6 for the crown region (a), springline (b), and invert (c), respectively. 

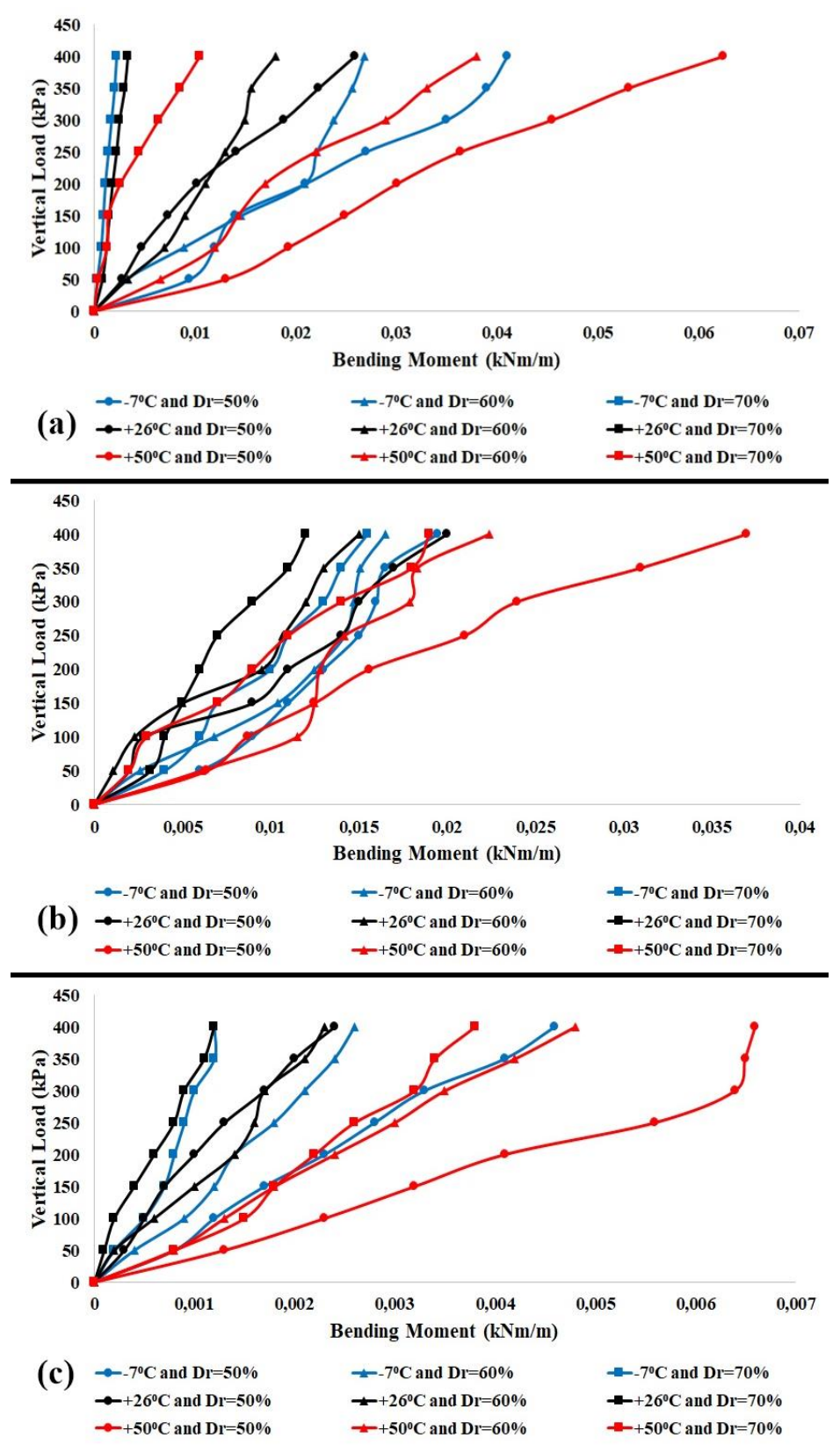

Figure 6. Bending moments for crown (a), springline (b), and invert (c) regions at $-7^{\circ} \mathrm{C},+26^{\circ} \mathrm{C}$, and $+50^{\circ} \mathrm{C}$.

In the tests carried out at $+50^{\circ} \mathrm{C}$, both crown and springlines were found to be $45 \%$ more than the experiments performed at $+26^{\circ} \mathrm{C}$. On the other hand, the decisive role of thermal effects in bending moment increases was obvious. It is an undoubted fact that the thermoplastic-viscoelastic characteristics of the HDPE materials are the main factor in the results that emerged.

According to the standards and published literature research, it is recommended that a dense bedding layer is used for flexible pipes and a relatively med-dense bedding layer is used for rigid pipes. In contrast, a loose bedding layer causes excessive vertical movement of the pipe in flexible pipeline applications and a dense bedding layer causes additional stress in rigid pipeline applications (Al-Mosawe et al., 2020; Howard \& Rahman, 2020). Given this framework, the bedding layer was filled and fully compacted since flexible pipes were used in this study. Minimal bending moments were observed in the invert 
region for all experiments, as expected given they were filled in accordance with the references. In addition, the bending moment values under variable temperature and relative density conditions gave results in parallel with the displacements read from LVDTs for all the experiments.

As a result of comprehensive laboratory experiments, it was found that temperature conditions as well as relative density and loading conditions, caused significant behavioral changes. The relative density of the trench increased the bedding capability of the soil along the vertical and lateral axes, and it increased the load-bearing characteristics in the pipe section. For the densest soil cases under all variable temperature conditions, the absorption of the stresses from the trench surface, and the measured deformations at the pipe walls showed significant decreases compared to the loosest soil cases.

\section{Conclusions}

The results obtained within the scope of thermal and cooling processes applied to the HDPE transfer lines are as follows:

1. The controlled temperature values applied with the thermal stripes placed on the pipe sample became determinant in the behavior of the pipe due to the characteristic features of the polymer material over each temperature range. Thus, the displacement values for both crown and springlines of the pipe section increased with temperature increases.

2. Finally, this study emphasized that the effects of temperature both during and after the production process in pipe design and quality-compliance tests should be examined together with the physical factors affecting the HDPE pipe.

Author contributions: Erenson and Terzi conceived of the presented idea and conducted laboratory experiments. Terzi designed the test box and Erenson installed the measuring assembly and wrote the manuscript. Polat carried out the thermal and cooling processes. Polat and Erenson collected, calculated, and processed the data.

Acknowledgments: We would like to show our appreciation to the Kuzeyboru for their support during the HDPE material supply and R\&D studies. We would also thank the Aksaray University Scientific Research Projects Unit (BAP 2018-051), which provided financial support for the development of laboratory facilities in the preparation stages of the experimental setup.

Conflicts of interest: The authors declare that they have no known competing financial interests or personal relationships that could have appeared to influence the work reported in this paper.

\section{References}

Al-Mosawe, M. J., Said, A. I., \& Dawood, A. O. (2020). Effect of bedding compaction on the behavior of buried plain concrete pipes. Key Engineering Materials, 857, 89-98. https://doi.org/10.4028/www.scientific.net/KEM.857.89

Alawaji, H. A. (2004). Performance of buried HDPE pipes at elevated temperatures. Electronic Journal of Geotechnical Engineering, 1(19).

ASTM D2321-00. (2000). ASTM D2321-00, Standard Practice for Underground Installation of Thermoplastic Pipe for Sewers and Other Gravity-Flow Applications. https://doi.org/10.1520/D2321-00

ASTM D2487_06. (2006). ASTM D2487 - 06, Standard Practice for Classification of Soils for Engineering Purposes (Unified Soil Classification System). https://doi.org/10.1520/D2487-06

Callister, W. D., \& Rethwisch, D. G. (2015). Fundamentals of Materials Science and Engineering, An Integrated Approach (5th ed.). Wiley.

Cheng, J. J. (2008). Mechanical and chemical properties of high density polyethylene: effects of microstructure on creep characteristics [PhD Thesis, University of Waterloo, Ontario, Canada]. http://hdl.handle.net/10012/4121

Gabriel, L. H., \& Moran, E. T. (1998). Service life of drainage pipe. National Academy Press.

Howard, A., \& Rahman, S. (2020). Review of design methods in AWWA manuals for various flexible pipe. Pipelines 2020 , $336-345$. https://doi.org/10.1061/9780784483213.037

Kapischke, M., \& Pries, A. (2014). Theodor Billroth's vision and Karl Ziegler's action: Commemoration of the 40th day of death and the 50th anniversary of conferment of Nobel Prize for Chemistry of Karl Ziegler. Surgery (United States), 155(2), 347-349. https://doi.org/10.1016/j.surg.2013.10.022 
Khademi-Zahedi, R., \& Alimouri, P. (2018). Finite element analysis to the effect of thermo-mechanical loads on stress distribution in buried polyethylene gas pipes jointed by electrofusion sockets, repaired by PE patches. Energies, 11(10). https://doi.org/10.3390/en11102818

Krishnaswamy, R. K. (2005). Analysis of ductile and brittle failures from creep rupture testing of high-density polyethylene (HDPE) pipes. Polymer, 46(25), 11664-11672. https://doi.org/10.1016/j.polymer.2005.09.084

Laidlaw, T. C. (1999). Influence of local support on corrugated HDPE pipe. MSc Thesis, The University of Western Ontario, Faculty of Graduate Studies.

Lepoutre, P. (2013). The manufacture of polyethylene. X-Polymers-J-Polyethylene, Transpak Industries Ltd.

Li, Z., Zhu, H., Kong, X., \& Seibi, A. (2012). Combined effect of temperature and soil load on buried HDPE pipe. Advanced Materials Research, 452-453, 1169-1173. https://doi.org/10.4028/www.scientific.net/AMR.452-453.1169

Liang, J. Z. (2019). Melt strength and drawability of HDPE, LDPE and HDPE/LDPE blends. Polymer Testing, 73, 433-438. https://doi.org/10.1016/j.polymertesting.2018.12.007

Merah, N., Saghir, F., Khan, Z., \& Bazoune, A. (2006). Effect of temperature on tensile properties of HDPE pipe material. Plastics, Rubber and Composites, 35(5), 226-230. https://doi.org/10.1179/174328906X103178

Patel, B. D., \& Srinivas, A. R. (2012). Validation of experimental strain measurement technique and development of force transducer. International Journal of Scientific \& Engineering Research, 3(10). http://www.ijser.org

Polat, N. (2020). Investigation of deformation properties of high-density polyethylene pipes under thermal effects. MSc Thesis, Graduate School of Natural and Applied Sciences, Aksaray University, Aksaray, Turkey.

Sadr-Al-Sadati, S. A., \& Jalili Ghazizadeh, M. (2019). The experimental and numerical study of water leakage from high-density polyethylene pipes at elevated temperatures. Polymer Testing, 74, 274-280. https://doi.org/10.1016/j.polymertesting.2019.01.014

Seymour, R. (1989). Pioneers in Polymer Science. In F. B. Seymour (Ed.), Chemists and Chemistry (1st ed.). Springer Netherlands. https://doi.org/10.1007/978-94-009-2407-9

Shaidullin, N. M., Salakhov, I. I., Borisenko, V. N., Tavtorkin, A. N., \& Nifant'ev, I. E. (2020). Structural, rheological, and mechanical properties of binary compounds based on high-density polyethylene and linear low-density polyethylene. Russian Journal of Applied Chemistry, 93(8), $1179-1187$. https://doi.org/10.1134/S1070427220080108

Tarani, E., Terzopoulou, Z., Bikiaris, D. N., Kyratsi, T., Chrissafis, K., \& Vourlias, G. (2017). Thermal conductivity and degradation behavior of HDPE/graphene nanocomposites: pyrolysis, kinetics and mechanism. Journal of Thermal Analysis and Calorimetry, 129(3), $1715-1726$. https://doi.org/10.1007/s10973-017-6342-0

Tavman, I., Aydoğdu, Y., Kök, M., Turgut, A., \& Ezan, A. (2011). Measurement of heat capacity and thermal conductivity of HDPE/expanded graphite nanocomposites by differential scanning calorimetry. Archives of Materials Science, 50(1), 56-60. www.archivesmse.org

Terzi, N. U. (2007). Gömülü borulara etkiyen düssey ve yatay yüklerin boru stabilitesine olan etkilerinin araştırllması. PhD Thesis, Yildiz Technical University, Graduate School of Natural and Applied Sciences, Istanbul, Turkey.

Trautmann, C. H., \& O’Rourke, T. D. (1985). Lateral force-displacement response of buried pipe. Journal of Geotechnical Engineering, 111(9), $1077-1092$. https://doi.org/10.1061/(ASCE)0733-9410(1985)111:9(1077)

Ural, N., \& Gergin, A. (2020). Foundation design on problematic soils with high underground water level. Revista de La Construccion, 19(3), 233-245. https://doi.org/10.7764/RDLC.19.3.233 